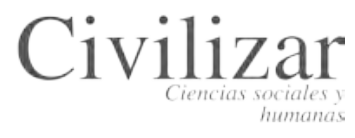

ISSN 1657-8953 e-ISSN: 2619-189X

\title{
Aproximaciones al concepto de imaginario social
}

\author{
Approaches to the Concept of Social Imaginary
}

Gustavo O. García Rodríguez ${ }^{\S}$

"Artículo de reflexión. Producto de la investigación Imaginarios de mujeres que ejercen la prostitución en Bogotá sobre los hombres que hacen uso de sus servicios sexuales (2017) para optar el título de magíster en Estudios Sociales de la Universidad Pedagógica Nacional.

$\S$ Sociólogo, Magíster en Estudios Sociales. Profesor de tiempo completo en la Especialización en Gestión Asociada de la Facultad de Ciencias Humanas y Sociales, Corporación Universitaria Minuto de Dios, Bogotá - Colombia.

Correo electrónico:

gustavo.garcia-r@uniminuto.edu.co.

(iD) 0000-0002-7159-8439

\section{Cómo citar:}

García-Rodríguez, G. (2019). Aproximaciones al concepto de imaginario social. Civilizar: Ciencias Sociales y Humanas, 19(37), 31-42. doi: 10.22518/usergioa/ jour/ccsh/2019.2/a08

\section{Resumen}

El artículo ofrece una serie de elementos para introducir al lector en la comprensión del concepto de imaginario social, concepto polivalente que cuenta con una importante tradición y amerita un acercamiento minucioso; un concepto abierto que, en la actualidad, se nutre de perspectivas que lo enriquecen y matizan. En respuesta a dicha situación, se exponen algunos puntos para situar los referentes de su discernimiento, lo que a su vez lo diferencia de conceptos y términos que suelen ubicarse como equivalentes. También se presentan las ideas centrales que, frente al mismo, han desarrollado tres autores que hacen parte de dos corrientes intelectuales: Cornelius Castoriadis, Manuel Antonio Baeza y Juan Luis Pintos.

Finalmente, se destaca la riqueza conceptual del imaginario social, su utilidad en el debate teórico-metodológico y práctico de la ciencia social, así como se pretende estimular la discusión e interés al rededor del mismo. En particular, se resalta la posibilidad que abre para contrarrestar el anquilosamiento que produce el afán de proponer y hacer uso de conceptos definidos y cerrados, una suerte de lugar común de la "ciencia verdadera”, ofreciendo caminos innovadores para el ejercicio de la ciencia social en un contexto tan maleable y dúctil como el contemporáneo y, que al ser situado en el escenario latinoamericano y nacional, encuentra panoramas contradictorios y por qué no, hasta irracionales.

\section{Palabras clave}

Ciencia verdadera, imaginario, imaginarios sociales, significaciones imaginarias, corrientes intelectuales, hermenéutica.

\section{Abstract}

This article offers a series of elements to introduce the reader to the understanding of the concept of social imaginary. This is a polyvalent concept with an outstanding tradition that deserves a detailed approach and that, at present, is nourished by perspectives that enrich and nuance it. In this situation, the references of its discernment are placed, which in turn differentiates it from concepts usually located as equivalent. The central ideas developed by Cornelius Castoriadis, Manuel Antonio Baeza and Juan Luis Pintos, who are part of two intellectual currents, are also presented.

Finally, the text highlights the conceptual richness of the social imaginary and its usefulness in the theoretical-methodological and practical debate of social science and aims to stimulate the discussion and interest around it. In particular, it emphasizes the possibility that it opens to counteract the stagnation produced by the eagerness to propose and make use of defined and closed concepts, a sort of commonplace of "true science". Moreover, the search offers innovative paths for the exercise of social science in a context as malleable and ductile as the contemporary one and that, when placed on the Latin American and national scenario, finds contradictory and even irrational views.

\section{Keywords}

True science, imaginary, social imaginary, imaginary meanings, intellectual currents, hermeneutics. 


\section{Introducción}

Poco a poco, el concepto de imaginario social ha ido ganando terreno en los debates de la ciencia social, así como de la sociología en particular. De reciente aparición (años ochenta del siglo pasado) en el debate académico, ha logrado ganarse un lugar en las aulas y sobre terreno - los ejercicios de investigación que apelan a él así lo corroboran- como concepto eje para comprender el mundo, así como para ser cuestionado y discutido ${ }^{1}$. La ausencia de una definición unívoca, sus referencias a elementos intangibles de la sociedad y los retos en su traducción metodológica, figuran como nodos de sus críticas y, probablemente, como razones de su lenta inserción en el escenario académico formal.

Lo anterior no implica, en absoluto, que estemos tratando de un concepto que deba desestimarse o asumirse como débil. Su arqueología puede rastrearse en autores de amplia referencia como Aristóteles o Durkheim, entre muchos otros; más bien, ha logrado posicionarse en medio de la controversia que suscita, generando la inconformidad de las posturas teóricas más férreamente ligadas a la tradición empírico-racionalista, lógicoracional o nomotética (Cegarra, 2012). El concepto de imaginario social permite hacerse a ricas lecturas de lo social al ofrecer interesantes elementos de juicio y análisis, sin que por ello se sacrifique el rigor conceptual o metodológico; invita más bien a posibilitar perspectivas abiertas y polifónicas que la mayoría de las veces se opacan por la necesidad de abrazar la certeza que ofrecen conceptos "más" claros y distintos.

Al inicio, trabajar con conceptos como el de imaginario social podría percibirse como un reto de gran envergadura, sin embargo, y apelando a una mirada más rigurosa, posee llamativas porosidades que permiten filtrar universos de sentido y significado ricos en contenido, que permiten acercarse al andamiaje menos evidente de eso que llamamos la vida cotidiana.

Así las cosas, léase lo que sigue como una de muchas puertas de entrada al universo de los imaginarios sociales, esperando que sus cualidades y características llamen la atención del lector por las dudas e intereses que puedan fundar, así como por las inquietudes e, incluso, reparos que edifique.

\section{Ideas introductorias al concepto} de imaginario social

El concepto de imaginario social ha cobrado un papel relevante en el campo de los estudios sociales, especialmente en el contexto contemporáneo; ha permitido revitalizar los debates teórico-conceptuales y metodológicos que en cierto momento del pensamiento social se vieron estancados, y aparece como una "herramienta de interpretación y conocimiento de la realidad social, utilizada inicialmente a un nivel individual" (Arribas, 2006, p. 18). Cobra un papel central en las discusiones académicas que optaron por referentes alternativos, paradigmas menos estáticos, conceptos menos "claros y distintos" - para parodiar los requerimientos filosóficos racionalistas-. El imaginario social "estaría alejado de los paradigmas clásicos, los cuales operarían jerarquizando el conocimiento. En cambio, este nuevo enfoque propone integrar anomalías, flexibilidad y universalidad" (Pintos y Aliaga, 2012, p. 11).

Manuel A. Baeza (2000) denomina a los imaginarios sociales como "la propuesta conceptual más significativa de los últimos años”, así como un concepto "extremadamente potente en su capacidad de desbaratar muchas de las categorías en uso corriente en las ciencias sociales" (pp. 8-9). Podemos rastrear sus orígenes en el siglo XIX como un dominio del espíritu desdeñado por la razón, a la vez que íntimamente ligado a la imaginación como facultad psicológica de engendrar y utilizar imágenes. A mediados del siglo XX con el declinar de una cierta concepción de la psicología y bajo la presión de las ciencias humanas, la perspectiva de la imaginación fue suplantada por el problema del imaginario: un estudio de las producciones de imágenes, sus propiedades y sus efectos (Wunenburger, 2003, p. 5; citado por Belli, López, y Romano, 2007, p. 105).

El imaginario surge como una cuestión individual, sin embargo, es necesario aclarar que se torna social en tanto pasa a ser compartido y aceptado por la sociedad, al punto de hacerse común al interior de grupos concretos.

Los estudios sobre imaginarios sociales vienen a ser una forma de generación de nuevo conocimiento - y por lo tanto de poder hacer-, especialmente en un momento en que se percibe en las ciencias sociales un vacío de carácter ontológico (Coca et al., 2011; citado por Randazzo, 2006, p. 86). 
Vale resaltar de nuevo que, desde su aparición en las discusiones académicas, el concepto de imaginario social ha debido enfrentarse a los juicios que ven en él una noción pre-científica, ligada más a la literatura y las artes que a un ejercicio de la razón científica. La revalorización antropológica de lo imaginario pasa, entonces, por el redescubrimiento de una lógica peculiar de lo aparentemente ilógico, por la dignificación de aquellos órdenes de la experiencia social irreductibles al modelo del discurso imperante desde la episteme racionalista y su derivado, la Ilustración (Carretero, 2004, p. 2).

El imaginario hace parte de lo que se acepta como real; estructura y constituye la realidad socialmente instituida (Carretero, 2004); descansa en un orden experiencial alternativo al paradigma racionalista predominante. Paradigma que privilegió el quehacer científico sobre elementos como la imaginación; Cornelius Castoriadis puede identificarse como uno de los principales intelectuales en entrar en su rescate.

La imaginación fue ignorada, a juicio de Castoriadis (2002, p. 94), hasta el siglo XVIII, cuando Kant la retoma como "imaginación trascendente", o sea: «la imaginación requerida para abarcar el conocimiento cierto y no empírico». Sin embargo, Castoriadis afirma que Kant, en la segunda edición de la obra, finalmente reduce la fuerza y la importancia a la imaginación. Heidegger trajo de nuevo el tema como cuestión filosófica, los movimientos de la historia de la imaginación y la crítica a la noción kantiana de imaginación trascendental (Hurtado, 2008, p. 86).

De allí que la veracidad en el imaginario no se base en los criterios de verdad o falsedad que establece la epistemología de la ortodoxia positivista, apunta más bien a desmitificar el axioma racionalista. Esto no implica que metodológicamente estemos frente a un concepto inoperable desde la investigación; en efecto, puede estudiársele de forma casi literal "a través de temas, relatos, motivos, tramas, composiciones o puestas en escena, capaces de abrir un significado dinámico dando lugar siempre a nuevas interpretaciones dado que sus imágenes y narraciones son siempre portadoras de un sentido simbólico o indirecto" (Solares, 2006, p. 130). En tal orden de ideas posibilitaría identificar y analizar las luchas, tensiones y hasta las emancipaciones que se libran al interior de la sociedad (Randazzo, 2012).

Falleti (2006) refiere que el imaginario social "introduce una perspectiva socio-histórica a partir de la cual estudia la génesis de las significaciones imaginarias" (p. 84), es decir hace referencia la "creación de nuevas significaciones" (p. 84), lo que da la posibilidad de estudiar el curso de transformación de los significados que atribuye una sociedad, así como las prácticas de esas significaciones derivadas. Se trata de "una noción que permite indagar el hacer, pues las significaciones sociales imaginarias son definidas como las formas de ser, pensar y actuar de las personas" (pp. 84-85).

Quizás es por estas cualidades instauradas por el imaginario social respecto de la racionalidad ilustrada, que para Solares se le ha tratado peyorativamente como una noción pre-científica, en el ámbito de las ciencias humanas:

No sólo suele ser fuente de numerosas imprecisiones sino, generalmente, de franco rechazo y malos entendidos. Cabe notar que de hecho, tanto en español como en francés, el término se inscribe de manera muy reciente en el vocabulario académico mientras que en inglés, hasta la fecha, no se tiene un equivalente preciso. (Solares, 2006, p. 130).

Habitualmente se le liga a las instituciones y las representaciones sociales que lo encarnan como la Iglesia o el Estado (Randazzo, 2012), haciendo complicado percibir este concepto por los niveles de legitimidad que una institución como estas pude llegar a tener, "pocas veces es utilizada con pertinencia y rigor, con lo cual sigue siendo una noción al uso, que de alguna forma se puede intuir, pero que difícilmente se logra explicar" (Randazzo, 2012, p. 78).

Destáquese a este respecto que representaciones e imaginarios no son figuras equivalentes: las representaciones sociales operan como precodificaciones que el individuo tiene en cuenta para desempeñarse en la sociedad, de allí su carácter más subjetivo; precodificaciones que no por ello dejan de depender de una sociedad particular en las que cobran cuerpo. El imaginario, por su parte, opera como matriz de sentido que tiende a imponerse ${ }^{2}$ como una forma de leer la vida social (Cegarra, 2012).

No se pierda de vista que lo imaginario tiene su hábitat original en sustratos tan amplios como la danza, los cantos, los chistes, los juegos, los cuentos y leyendas, la abstención, los silencios, las astucias, la artimaña, la burla, la ironía, el cinismo, el cine, entre otros. Así también, que el imaginario posee un gran potencial liberador, de oponer resistencia ${ }^{3}$, de generar novedad (Bergua, 2005).

Lo imaginario no es lo mismo que lo simbólico4; lo simbólico está ligado a la razón, a lo empírico; lo 
imaginario, a la magia, a lo difuso. Según Bergua (2005):

El tipo de significación que procuran uno y otro registro, el simbólico y el imaginario, es distinto. Mientras el simbólico produce sentido según las relaciones digitalizadas que se dan entre los significantes, en los que el sujeto y los objetos están re-presentados (suplantados), en el registro imaginario el efecto de sentido es producido por una relación más analógica entre las imágenes así como de estas con la realidad. Por otro lado, el predominio de uno u otro modo de significación, pone en marcha dos tipos de conocimiento diferentes, el mito y el logos [Morin, 1988:173]". (p. 41).

De igual forma, lo imaginario no se debe confundir con la mentalidad, la mitología, la ideología, la ficción, o la imaginería, ni tampoco reducirse a un signo lingüístico; estaría definido "más por sus estructuras antropológicas que por sus referencias semióticas, empíricas o cuantitativas. Su función primordial consiste en "reelaborar o crear de nueva forma las conminaciones histórico-sociales dadas y no meramente reflejadas en una pasiva e imperfecta adecuattio" (Solares, 2006, p. 132). Para precisar aún más la distinción entre el imaginario y la imaginación; vale la pena enfatizar en los siguientes puntos:

- La imaginación es una capacidad individual que imita o recrea la realidad, la cual, mediante el uso de imágenes procede a manifestarla. El imaginario, por su parte, no es una facultad humana, es más una suerte de gramática, un esquema referencial que permite interpretar la realidad, socialmente legitimado, intersubjetiva e históricamente determinado.

- La imaginación reproduce la realidad; mientras que el imaginario opera como matriz de significados que orientan los sentidos que se le atribuyen a nociones de la vida compartidas por una sociedad.

- La imaginación es entonces una facultad humana innata; el imaginario, condición propia de la vida en sociedad.

(Cegarra, 2012, p. 3)

Estos son algunos puntos en los que el concepto de imaginario encuentra cierto nivel de consenso y vale la pena destacar: representan esquemas, marcos, matrices de sentido ${ }^{5}$, que permiten a los sujetos crear, construir/deconstruir, resignificar, conocer; no son la sumatoria de imaginarios individuales; necesitan reconocimiento colectivo; tienen un carácter incompleto, dinámico y móvil (Shotter, 2002); tienen atributos reales así no se puedan anclar al espacio o al tiempo concretos; son formas creativas de vivenciar el futuro construyendo nuevas maneras de vivir; son una creación incesante e indeterminada (Hurtado, 2004).

Ahora bien, las siguientes son otras cualidades que el concepto de imaginario social posee y que cerrarían esta apretada síntesis de elementos que se han venido exponiendo:

- Su flexibilidad: no opera como concepto determinante, rígido, permanente y estable. Flexibilidad de gran utilidad en sociedades como en las que vivimos en la actualidad, que se destacan por la fluctuación, la dinámica, la transformación; si se quiere por el caos y la poca estabilidad social. El imaginario "permite y procura la realización de microajustes permanentes que refuerzan su utilidad práctica" (Arribas, 2006, p. 22).

- Su carácter socializante: pues la realidad social no debe ser sólo concebida por los investigadores $\mathrm{y} / \mathrm{o}$ pensadores, académicos, especialistas, etc., debe tener en cuenta a la comunidad de individuos no expertos que lo vivencian en su cotidianidad; de esta forma, puede mostrar potencia en la conformación o afianzamiento de la conciencia colectiva de los sujetos (Arribas, 2006). Esto quiere decir que las interpretaciones sobre la vida deben convalidarse en el grupo social para que puedan lograr un grado importante de legitimidad, no siendo una cuestión impuesta desde quienes se auto-confieren las últimas palabras frente a una situación

- Es fuente de creación de posibilidades alternativas de realidad; mediante la irrealidad fractura lo considerado como real, se controvierte como alternativa ${ }^{6}$ (Carretero, 2004).

- Es un recurso cultural para hacer frente al destino del hombre (Carretero, 2004).

- Es el resultado del despliegue de una fantasía que intenta restaurar una identidad originaria del sujeto, que había sido fracturada como consecuencia de las pautas institucionalizadas de socialización que le habían conferido una identidad racional (Carretero, 2004).

- Expresa una demanda por restaurar un desequilibrio causado por las carencias, los desajustes y desarreglos culturales; un ansia 
por revelarse y trascender el destino natural (Carretero, 2004).

- Es el resultado de una proyección fantasiosa que, una vez solidificada, ilumina modos de reinvención de la realidad (Carretero, 2004).

- $\quad$ Nace del desajuste entre lo real y lo posible; es una instancia que busca re-encantar la existencia (Carretero, 2004).

- Remite tanto al aspecto representativo y verbalizado de una expresión como al aspecto emocional y afectivo más íntimo de esta (Solares, 2006, p. 130).

- El imaginario posee dos dimensiones más a considerar: la cognitiva y la hermenéutica. La primera hace referencia a que el imaginario se liga a marcos "que conforman desde las metas, formas de actuar y valorar, hasta la política y las instituciones" (Randazzo, 2012, p. 81); una suerte de pensar abstracto o capacidad psíquica. La segunda, en tanto permite entender el sentido que socialmente se le atribuye a las cosas, pues son esquemas de significado que nos permiten entender la realidad. De alguna forma, predeterminaría lo que es posible de acontecer en función de lo que puede ser entendido dentro de unos esquemas pre-estructurados, pero también engloba las estructuras bien fraguadas, como las instituciones (Randazzo, 2012).

Ya contamos con algunos elementos generales que presentan una mirada inicial sobre el concepto de imaginarios sociales, huelga decir que el debate en torno a su concepción ha sido amplio y ha contado con matices importantes, esto tal vez y para darle cierta robustez teórica al ser concebido por un sector del público académico como "poco científico". Con todo, se ha ofrecido una lectura más detallada que aporta unos postulados mejor elaborados en lo teórico, los cuales serán presentados a continuación.

\section{Los imaginarios sociales en el discurso teórico-conceptual de la ciencia social}

Pintos y Aliaga (2012) establecen dos corrientes intelectuales importantes sobre imaginarios sociales: la francesa y la iberoamericana. La primera, encuentra sus raíces intelectuales en los planteamientos de Emile Durkheim, en sus estudios sobre las representaciones sociales, en su obra Las formas elementales de la vida religiosa, de 1912. Acorde lo proponen Pintos y Aliaga (2012) "podríamos decir que posiciona el factor imaginario como relevante para la comprensión de la sociedad" (p. 14). Gilbert Durand es un exponente contemporáneo de esta tradición, desde una postura antropológica, con su obra Las estructuras antropológicas de lo imaginario, de 1960. Allí conjuga los factores arquetípico, simbólico y mítico para sustentar el concepto de imaginario. Cornelius Castoriadis es, sin duda alguna, el autor más reconocido en materia de imaginarios sociales, no solo al interior de esta corriente, sino en el plano general de las ciencias sociales; su obra más reconocida es La institución imaginaria de la sociedad, de 1975, donde el autor "realiza una revisión de la ontología filosófica y logra posicionar el imaginario como un factor elemental en la configuración de la sociedad como parte constitutiva de lo real, y el valor de las significaciones imaginarias en el orden social" (Pintos y Aliaga, 2012, p. 14). Otros dos autores que son destacados al interior de esta corriente, que trabajan al imaginario social en relación con la modernidad avanzada o posmodernidad, son Georges Balandier y Michel Mafesoli.

En el caso español destaca Juan Luis Pintos ${ }^{7}$ con su libro de 1995 Los imaginarios sociales: la nueva construcción de la realidad social; que, apoyado en la socio-cibernética propone "un enfoque sociológico de acercamiento a los imaginarios sociales desde el constructivismo sistémico como mecanismo de comprensión de la realidad y del orden social" (Pintos y Aliaga, 2012, pp. 14-15). Manuel Antonio Baeza, chileno, publica en el año 2000 un texto titulado Los caminos invisibles de la realidad social. Ensayo de sociología profunda sobre los imaginarios sociales; allí se denota su corte más ligado a la fenomenología, así como en una producción posterior titulada Mundo real, mundo imaginario social de 2008.

Enrique Carretero Pasín, español, presenta en 2007 su texto Imaginarios sociales y crítica ideológica. Una perspectiva para la comprensión de la legitimación del orden social; el autor "se centra en la importancia de diferenciar el imaginario de la ideología y comienza a desarrollar un nutrido trabajo teórico en cuanto a la relación del imaginario y la posmodernidad" (Pintos y Aliaga, 2012, p. 15). Otros dos destacados representantes de la corriente iberoamericana son (en línea con la tradición hermenéutica) Celso Sánchez Capdequí, con sus textos Imaginación y sociedad: una hermenéutica creativa de la cultura, de 1999 y Las máscaras del dinero: 
el simbolismo social de la riqueza (2004); y Josetxo Beriain, con su texto intitulado Las contradicciones culturales de la modernidad (2007).

Del escenario latinoamericano, Pintos y Aliaga destacan a Armando Silva con su texto de finales de los noventa Imaginarios urbanos, asimismo resaltan:

El activo grupo de investigadores de la Universidad Tecnológica de Pereira dirigido por la doctora Olga Lucía Bedoya (Imaginario femenino y ciudad, 1999) que ha incorporado a la investigación urbana planteamientos constructivistas con muy interesantes resultados. En la Universidad Nacional de Colombia, Bogotá, el IECO (Instituto de Estudios en Comunicación y Cultura, bajo la dirección, entonces de la profesora Neyla Pardo) organizó un Seminario Internacional sobre Imaginarios sociales y publicó posteriormente una muy interesante obra colectiva bajo el título Proyectar Imaginarios (2006), con colaboraciones de autores latinoamericanos y españoles. (2012, p. 17).

Ahora bien, del grupo arriba señalado, profundizaremos en tres autores que se han considerado centrales a la hora de establecer una discusión teórica de base en materia de imaginarios sociales; Cornelius Castoriadis, por darle una especie de estatus fundacional al concepto, en el marco de las ciencias sociales; Antonio Baeza y Juan Luis Pintos ya que exponen una interesante convergencia en medio de la distancia que pueden presentar en un primer momentos sus influencias: la de Baeza, ligada a la tradición fenomenológica, y la de Pintos, al constructivismo sistémico.

\section{Cornelius Castoriadis (1922-1997).}

Para Castoriadis, el imaginario es un fenómeno tanto individual como colectivo, puede comprenderse como un patrimonio representativo, esto es, "como el conjunto de imágenes mentales acumuladas por el individuo en el curso de su socialización" (Dittus, 2006, p. 167); desde su imaginación ${ }^{8}$, el ser humano se construye una especie de filtros socialmente reconocidos, en marcos culturales y momentos históricos específicos (Dittus, 2006, p. 173). Un punto central en la propuesta de Castoriadis es atribuirles a los imaginarios sociales la calidad de "factor de equilibrio psicosocial. Esto último ya que actúan compensando las diferencias y vacíos cognitivos, superando el excesivo racionalismo de la modernidad" (Dittus, 2006, p. 172); de allí que para
Randazzo (2012), en la obra de Castoriadis, los imaginarios parecen tener esencia, un carácter propio.

En las elaboraciones que propuso Castoriadis se destaca la idea del imaginario instituyente, el cual hace referencia a ese universo fundante que le da sentido a las sociedades y que tendría por función principal dar cuenta de cómo

En la historia, desde el origen, constatamos la emergencia de lo nuevo radical, y si no podemos recurrir a factores trascendentes para dar cuenta de eso, tenemos que postular necesariamente un poder de creación, un vis formando, inmanente tanto a las colectividades humanas como a los seres singulares (Castoriadis, 2002, p. 94).

Para Castoriadis (1997), la idea de un imaginario instituyente puede ser, en principio, difícil de aceptar, puesto que señala a una potencia/potencialidad. Por lo tanto, los resultados o productos de dicha potencialidad son lo comúnmente identificable. Así, la imaginación tiene una tremenda capacidad creadora, de innovar la vida misma tanto individual como social. El imaginario instituyente sería entonces "esa facultad que es constitutiva de las colectividades humanas, y más generalmente, del campo sociohistórico" (Castoriadis, 2002, pp. 94-95); de tal forma que "ninguna sociedad puede perdurar sin crear una representación del mundo y, en ese mundo, de ella misma" (Randazzo, 2012, p. 85).

La sociedad es un sistema de interpretación del mundo propiamente dicho; de allí que Castoriadis desarrolle la idea relativa a la "institucionalización de un magma de significaciones imaginarias que garantiza la inteligibilidad y solidifica un sentido de realidad" (Randazzo, 2012, p. 84).

La referencia a Atenas y a los atenienses puede dar luces a este respecto: "porque Atenas existe, son necesarios los atenienses y no humanos en general; pero los atenienses son creados solamente en y por Atenas" (Castoriadis, 1997, p. 5). La sociedad es, entonces, tanto autoinstitución como autocreación, particular y específica.

Para Randazzo (2012), en la propuesta de Castoriadis hay una división del concepto de imaginario en dos planos, que cuentan con significaciones diferentes e independientes una de la otra:

Los primarios o centrales, que son creaciones $E x$ nihilo, instituciones imaginadas que no dependen sino de su misma idea para referenciarse, como Dios, la familia o el Estado. Los secundarios, que surgen y dependen de los primarios, por ejemplo la 
idea de ciudadano no puede concebirse sin la idea de Estado. Por eso estas representaciones son consideradas instrumentales, jugando un simple papel reproductor de los primarios. (pp. 85-86).

Además de la idea de imaginario instituyente, resalta la de significación imaginaria social. En principio, las significaciones imaginarias sociales no señalan una realidad o lógica concretas; sin embargo, por vía de manifestaciones particulares de las instituciones de una sociedad muestran haberse materializado y legitimado; es este entonces cuando dicha materialización se comprende como un imaginario social instituido. Para Castoriadis, "el imaginario social instituido se conforma por las significaciones imaginarias sociales y las instituciones cristalizadas, asegurando en la sociedad la repetición de las mismas formas que regulan la vida en sociedad" (Randazzo, 2012, p. 83).

Así pues, las significaciones imaginarias sociales se pueden entender con mayor amplitud como aquel mundo que:

Instaura las condiciones y las orientaciones comunes de lo factible y lo representable, de lo real y lo verdadero, de lo que es considerado objetivo. Las significaciones imaginarias sociales son las que hacen posible que los sujetos existan como sujetos y singularmente como una determinada forma de ser sujetos. Además, es necesario aclarar que ellas, en tanto hacen posible la existencia de los objetos, no podrán comprenderse por fuera de esa relación del objeto con su referente, ya que siempre éste es co-constituido por la significación imaginaria social correspondiente (Hurtado, 2008, p. 90).

Las significaciones imaginarias sociales son, además, creaciones libres e inmotivadas, ex nihilo; no obstante, coherentes y completas: "crean un mundo propio para la sociedad considerada, son en realidad ese mundo: conforman la psique de los individuos. Crean así una representación del mundo, incluida la sociedad misma y su lugar en ese mundo" (Castoriadis, 1997, p. 9).

Para Castoriadis, la oposición individuo/sociedad carece de sentido: el individuo es producto de la sociedad mediante la cual esta se perpetúa y desde la que se constata su existencia; no hay una oposición tal, "la verdadera polaridad es la polaridad sociedad/psique" (Castoriadis, 1997, p. 4). Psique y sociedad son dos polos irreductibles, de tal forma que la imaginación individual no puede por sí sola producir significación social; "la creación de signifi- caciones sociales imaginarias no surge de procesos naturales asociales, sino que es la sociedad la que se instituye así misma por medio de representaciones" (Dittus, 2006, p. 172).

El imaginario se ubica en lo social, es allí donde se da el movimiento entre lo instituido y lo instituyente. La imaginación tiene un carácter individual ${ }^{9}$ mientras el imaginario es social: "los imaginarios se refieren a lo social y a la dinámica de lo instituido y lo instituyente, a la potencia que tienen éstos en la formación de sujetos sociales" (Hurtado, 2008, p. 91). Esta dinámica entre lo instituido y lo instituyente goza de la cualidad dinámica y creadora que Castoriadis ha otorgado a al imaginario social. "La primera se refiere a que las significaciones sociales descansan sobre instituciones cristalizadas. Lo instituyente en cambio, se refiere a ese colectivo anónimo que dinamiza ciertas transformaciones sociales" (Etkin, 2017, p. 165).

El principal cuestionamiento ${ }^{10}$ que se le hace a los planteamientos de Castoriadis se propone desde el plano metodológico; "deja muchas preguntas desde el punto de vista metodológico, ya que no muestran los caminos a transitar cuando de investigar imaginarios se trata" (Hurtado, 2008, p. 85). Castoriadis no habría planteado una metodología propiamente dicha para acceder a la comprensión de las significaciones que poseen los imaginarios sociales, "sin embargo, sugería la necesidad de definir para ello un marco de comprensión social-histórico, pero igualmente una capacidad para comprender, mediante lo que es dicho, los elementos esenciales de lo que como tal no es dicho, de lo inefable e invisible" (Hurtado, 2008, p. 92).

\section{Manuel A. Baeza.}

Para Baeza (2000) la comprensión del concepto de imaginario social implica cuestionar la conciencia moderna, en específico, la visión moderna e instrumental de la conciencia; esto figura como central para el autor pues el imaginario social influye con contundencia los modos de pensar y actuar en sociedad. Teniendo en cuenta lo anterior,

Un imaginario - entendido aquí en términos sobre todo sociales - es una manera compartida por grupos de personas de representarse mentalmente el espacio y el tiempo. Algo así como un imaginar o idear socialmente, en donde se comparten, en una modalidad simbólica, formas y contenidos, es decir, significantes y significados, en los cuales dichos grupos se reconocen, aun cuando - en nuestra 
individualidad moderna - las intensidades de dichos reconocimientos sean variables. En un nivel de mayor abstracción, podemos decir, del mismo modo que lo hace el sociólogo español Juan Luis Pintos, que los imaginarios sociales son verdaderos esquemas de inteligibilidad de lo que es, en definitiva, una realidad invisible. Como tales, dichos imaginarios se levantan como auténticas matrices de sentido existencial, en ese caso colectivo. (p. 9).

Así mismo, los imaginarios sociales hacen las veces de "ejes de articulación del pensamiento y de la acción social" y de "formas creativas de vivenciar lo desconocido" (p. 10). El énfasis lo pone Baeza en la elaboración de sentidos subjetivos que se le atribuyen a los discursos o al pensamiento y, en particular, a la acción social, así esos sentidos figuren como opuestos a la racionalidad general (que es debilitada por esta vía); lo que se comprende como punto de vista es el otro elemento que los imaginarios sociales ayudan a edificar, pero sin perder de vista que toda elaboración de los sentidos subjetivos se da en medio de un contexto particular, signados por una historicidad que los caracteriza: "cada gran época histórica supone sus propios "paradigmas imaginarios", a partir de los cuales los contemporáneos deambulan sin horizonte de sentidos" (Baeza, 2000, p. 15).

Más interesante aún, el imaginario social no está preso en la determinación estructural que establecen momentos históricos particulares (la trampa espacio-temporal dice Baeza), posee un nivel de autonomía que le permite una mayor plasticidad y creatividad; "aun las más fuertes determinaciones sociales, antes de poder operar con toda su presunta eficiencia, han de ser procesadas, "digeridas" por subjetividades particulares, pudiendo por ellos ser, o bien aceptadas, o relativizadas, o hasta evitadas" (Baeza, 2000, p. 18). La relación entre imaginario y tiempo histórico no es unilateral ni mecánica, sino que la acción del imaginario puede extenderse a lo que se concibe como sinrazón o sinsentido:

Los imaginarios serían entonces construcciones fundacionales ex nihilo, ingenierías elementales con miras a contribuir a la inteligibilidad de lo constantemente experienciado, diversas composiciones que incorporan elementos heterogéneos que la actividad mental puede ser capaz de producir: creencias (categoría de "verdades" propias e indesmentibles), juicios, etc. (Baeza, 2000, p. 21).

Es el sujeto imaginante, hombres y mujeres de carne y hueso, quienes dan vida al imaginario social de manera simbólica ${ }^{11}$, son ellos/ellas con su subjetividad, en un contexto histórico-social concreto, quienes los expresan y convierten en prácticas de vida específicas. Por tanto, el imaginario es un fenómeno individual en su origen: "se presenta, no como una gramática ordenada de inteligibilidad del universo, sino como una composición relativamente libre e irrefutable, en la medida en que no ha de rendir cuentas a ningún tipo de racionalidad" (Baeza, 2000, p. 22); construye realidades independientemente del estatuto ontológico que se les atribuya.

Cuando estos imaginarios originalmente individuales se hacen sociales, ¿en qué punto son socializados? La respuesta inicial apunta a que un imaginario social no es la sumatoria de imaginarios individuales. En concreto, "los imaginarios pasarían a ser sociales porque se producirían, en el marco de las relaciones sociales, condiciones históricas y sociales favorables para que determinados imaginarios sean colectivizados, es decir instituidos socialmente" (Baeza, 200o, p. 25). La institución mayor de la sociedad es la sociedad misma ${ }^{12}$, figura que representa de buena medida el papel que cumplen las instituciones en cuanto a los imaginarios sociales.

Finalmente, Baeza expone la que denomina como una definición provisional que estima pertinente comprender el concepto de imaginario social:

Son composiciones ya socializadas en el tramado mismo de las relaciones sociales, con el propósito de dar inteligibilidad al cosmos, al mundo y a la sociedad, al mundo y a la naturaleza, a la vida desde sus orígenes y a la muerte, etc. ... deben ser considerados en tanto que la base misma de ese "mínimo común denominador" ideacional que cohesiona a los grupos sociales, cualquiera sea el tamaño de estos. (Baeza, 2000, pp. 33-34).

Provisional, por fortuna, además de central importancia en tanto destaca el papel cohesionador de los imaginarios.

\section{Juan Luis Pintos.}

Pintos $^{13}$, a diferencia de Baeza, se orienta por la influencia de la perspectiva sistémica, preocupándose por los problemas relativos al orden social y su relación con los imaginarios sociales. Establece tres elementos para la definición de los imaginarios sociales $^{14}$ :

1. Esquemas socialmente construidos: significa que su entidad tiene un elevado grado de abstracción, semejante a las referencias temporales que implican una determinada constancia en la secuencialidad, 
priorización y jerarquización de nuestras percepciones a través del código relevancia/opacidad socialmente diferenciado.

2. Que nos permiten percibir, explicar e intervenir: las operaciones complejas a las que se refieren estos verbos son posibles para nosotros porque disponemos de un mundo a nuestro alcance y una distribución diferenciada del conocimiento que posibilita unas referencias semejantes de percepción (espaciales, temporales, geográficas, históricas, culturales, religiosas, etc.), de explicación (marcos lógicos, emocionales, sentimentales, biográficos, etc.) y de intervención (estrategias, programas, políticas, tácticas, aprendizajes, etc.), todo ello referido al elemento siguiente.

3. Lo que cada sistema social diferenciado se tenga por realidad: no hay una única realidad, que se identificaría necesariamente con una verdad única. Nuestras sociedades contemporáneas no se configuran bajo el modelo de sistemas únicos, y de referencias absolutas, sino que están sometidas a procesos evolutivos de progresivas diferenciaciones sistémicas [N. Luhmann]. Aparecen así históricamente modos de comunicación diferenciada por códigos y programas por los que el sistema se vuelve funcional a las exigencias del entorno produciendo ámbitos específicos de operación [política, ciencia, derecho, economía, religión, etc.]. (Pintos, 2005, p. 43).

El imaginario social opera como un meta-código $^{15}$ en los sistemas sociales diferenciados, en el interior de un medio específico y propio de cada sistema (dinero, creencia, poder, etc.), a través del código relevancia/opacidad ${ }^{16}$ (lo visible/lo invisible), con lo que genera formas y modos que fungen como realidades (Pintos, 2005).

En consecuencia, el imaginario social contaría con funciones tales como: "producir una imagen de estabilidad en las relaciones sociales cambiantes; ... generar percepciones de continuidad en experiencias discontinuas; ... proporcionar explicaciones globales de fenómenos fragmentarios; ... permitir intervenir en los procesos construidos desde perspectivas diferenciadas" (Pintos, 2005, p. 46).

Con la propuesta del código relevancia/opacidad Pintos no solo ha expuesto una teoría de los imaginarios sociales desde una perspectiva sociológica, también ha situado una apuesta metodológica que funge como herramienta de descripción sociológica (Torres, 2015).
Para Baeza, la forma en que Pintos construye a los imaginarios sociales apunta a aquellas múltiples cosmovisiones (visiones del mundo, cosmologías, mitologías, estereotipos, entre otros) que los hombres construyen de diversa forma para permitir la elaboración de sentidos; señala también que los imaginarios sociales para Pintos tendrían finalmente las siguientes características:

a. Serían lugares o ámbitos de creación de imágenes con sentido que nos permiten acceder a la interpretación de lo social.

b. Representan lugares de lectura y codificación/ decodificación de los mensajes socialmente relevantes.

c. Corresponden a esquemas que permiten configurar/deformar la plausibilidad de los fenómenos sociales.

d. Serían no-representaciones concretas (signos, símbolos, etc.), pero sí esquemas (abstractos) de representación hacia los que se orienta la referencialidad social (el "poder", el "amor", la "salud", etc.)".

(Baeza, 2000, p. 136)

Nótese que tanto Pintos como Baeza han fungido como interlocutores, ambos han puesto sobre la mesa un rico debate acerca del concepto de imaginario desde sus perspectivas. Si bien existe un distanciamiento entre los dos (tal y como se refirió antes), lo valioso son las zonas en las que convergen y complementan sus puntos de vista, dando muestras de un verdadero diálogo de saberes, polivalente y dinámico.

\section{Consideraciones finales}

El estudio de los imaginarios sociales como herramienta conceptual para abordar la comprensión de la realidad ofrece una multiplicidad de posibilidades que el estudioso de lo social puede, con el rigor pertinente, apropiarse: hacerse a los universos de lo difuso, de los claro/oscuros, de las certezas móviles, son en estos momentos casi que un requerimiento de la ciencia social pues, como se señaló antes, el anquilosamiento de la reflexión teórico conceptual puede sacudirse contemplando vías alternativas a recorrer.

Encontrar en los elementos de la vida social, aún en los más solidificados de la misma, una serie de grietas que permiten reconocer niveles poco conocidos o regularmente esquivos, alentaría miradas renovadas, así como propuestas que, con cierto 
grado de novedad, robustezcan el ejercicio comprensivo del mundo circundante. De esa forma, y en línea con las ideas de Baeza (2000) sobre el imaginario, podría abrirse un espacio de comprensión de la móvil y vertiginosa conciencia moderna.

Desde una perspectiva dinámica, el entendimiento de las transformaciones de la sociedad, de las fibras que fundamentan su estructura y actuar en el cuerpo de sujetos concretos, se ubica al imaginario social como herramienta de primera mano a utilizar; al permitir doblar los lugares comunes y revisar las caras internas (los reversos) de lo que entendemos como instituido, se posibilitan muchos escenarios de polémica que son tan caros hoy en las aulas, centros de investigación, y demás espacios donde se produzca conocimiento.

Por otro lado, el fuerte desarrollo del análisis de los imaginarios sociales por parte de la corriente iberoamericana expone los avances de escenarios cercanos a nuestro contexto (latinoamericano), lo que muestra una sólida producción académica que oxigena el escenario internacional desde el habla hispana y desde entornos que descentran los focos de producción de conocimiento predominantes con dinámicas particulares y sugerentes.

Los reparos que se argumentan relativos a la inconsistencia conceptual del imaginario, así como su inclusión es un conglomerado teórico unificado, es ante todo una posibilidad para robustecer y ampliar la capacidad comprensiva del concepto; lejos está de convertirse en una razón para omitirlo o descreditarlo, ya que tal posición, además de monolítica y recalcitrante, cierra el rico y variado universo teórico que, en el campo de las ciencias sociales es, ante todo, dinámico. No se olvide la frase que se le atribuye a Voltaire cuando de certeza se trata, que si bien la duda es incómoda, la certeza es ridícula.

\section{Referencias}

Aliaga, F., y Pintos, J. (2012). Introducción: La Investigación social en torno a los imaginarios sociales: Un horizonte abierto a las posibilidades. Revista de Investigaciones Políticas y Sociológicas, 11(2), 11-17. Recuperado de http://seminariogceis.files. wordpress.com/2012/o8/monogrcza1fico-imaginarios-sociales.pdf

Arribas, L. (2006). El imaginario social como paradigma del conocimiento sociológico. Revista de Investigaciones Políticas y Sociológicas, 5(1), 13-12.
Baeza, M. (2000). Los caminos invisibles de la realidad social. Ensayo de sociología profunda sobre los imaginarios sociales. Santiago de Chile, Chile: Ediciones Sociedad Hoy.

Belli S., López C., y Romano, J. (2007). La excepcionalidad del otro. Athenea Digital, 11, 104-113. doi: $10.5565 / \mathrm{rev} /$ athenead/von11.342

Bergua, J. (2005). Lo social instituyente y la imaginación. Culturales, 1(1), 29-56. Recuperado de https:// www.redalyc.org/pdf/694/69410103.pdf

Carretero, E. (2004). La relevancia sociológica de lo imaginario en la cultura actual. Nómadas, 9, 1-9.

Castoriadis, C. (1997). El Imaginario social instituyente. Zona Erógena, 35, 1-9. Recuperado de http:// www.ubiobio.cl/miweb/webfile/media/267/Castoriadis $\% 20$ Cornelius $\% 20-\% 20$ El\%20Imaginario\%2oSocial\%2oInstituyente.pdf

Castoriadis, C. (2002). La institución imaginaria de la sociedad: El imaginario social y la institución (Vols. 1-2). Buenos Aires, Argentina: Tusquets Editores.

Cegarra, J. (2012). Fundamentos teórico espistemológicos de los imaginarios sociales. Cinta de Moebio, 43, 1-13. doi: 10.4067/So717-554X2012000100001

Etkin, M. (2017). Las organizaciones de la sociedad civil como imaginarios instituidos e instituyentes: Reflexiones desde la perspectiva de Cornelius Castoriadis. Revista Científica, 21(1), 161-171. Recuperado de https://publicacionescientificas.uces.edu.ar/ index.php/cientifica/article/view/413

Hurtado, D. (2004). Reflexiones sobre la teoría de imaginarios: una posibilidad de comprensión desde lo instituido y la imaginación radical. Cinta de Moebio, 21, 169-174. Recuperado de http://www. revistas.uchile.cl/index.php/CDM/article/viewFile/26119/27418

Hurtado, D. (2008). La configuración, un recurso para comprender los entramados de las significaciones imaginarias. Revista Latinoamericana de Ciencias Sociales Niñez y Juventud, 6(1), 81-110. Recuperado de http://www.scielo.org.co/pdf/rlcs/v6n1/ v6n1ao4.pdf

Dittus, R (2006). El imaginario social y su aporte a la teoría de la comunicación: seis argumentos para debatir. Cinta de Moebio, 26, 166-176. Recuperado de: https://www.moebio.uchile.cl/26/dittus.html

Falleti, V. (2006). Los problemas de la construcción del conocimiento en las ciencias sociales. Una mirada crítica sobre las nociones clásicas el tipo ideal y la representación. Universitas Humanística, 62(62), 
71-89. Recuperado de: https://revistas.javeriana.edu.co/index.php/univhumanistica/article/ view/2205

Nassif, R. (2011). ¿Es posible conocer la realidad? Nuevos y viejos debates del siglo XXI. Buenos Aires, Argentina: Ediciones Cinco.

Pintos, J. (1995). Los imaginarios sociales. La nueva construcción de la realidad social. Maliaño (Cantabria), España: Editorial Sal Terrae.

Pintos, J. (2005). Comunicación, construcción de realidad e imaginarios sociales. Utopía y Praxis Latinoamericana, 10(29), 37-65. Recuperado de: https://www.redalyc.org/pdf/279/27910293.pdf

Randazzo, F. (2012). Los imaginarios sociales como herramienta. Imagonautas, 2(2), 77-96. Recuperado de http://imagonautas.gceis.net/sites/imagonautas.gceis.net/files/images/5.-_randazzo.pdf

Solares, B. (2006). Aproximaciones a la noción de imaginario. Revista Mexicana de Ciencias Políticas y Sociales, 48(198), 129-141. doi: 10.22201/ fcpys.2448492xe.2006.198.42543

Shotter, J. (2002). Realidades conversacionales. La construcción de la vida a través del lenguaje. Buenos Aires, Argentina: Amorrortu.

Torres, M. (2015). La evolución del concepto de imaginarios sociales en la obra publicada de Juan Luis Pintos de Cea Navarro. Imagonautas, 6, 1-14. doi: https://doi.org/10.22517/25393812.12281

\section{Notas}

1 A este respecto vale la pena destacar el papel que ha venido desempeñando recientemente la revista Imagonautas de la Universidad de Vigo como medio de difusión y de debate académico alrededor de los imaginarios. Para conocer la revista revisar el link: http://imagonautas.webs.uvigo.gal/index.php/imagonautas/about

De igual forma, en el contexto italiano vale destacar la revistaIm@go. A Journal of the Social Imaginary. Para conocer la revista revisar el link: http://cab. unime.it/johttp://cab.unime.it/journals/index.php/ IMAGO/index

2 "El sujeto simplemente "lo padece" por encima de sus propias experiencias vitales. Esto no quiere significar que los imaginarios sociales sean inmodificables o históricamente permanentes, por el contrario, cada época histórica a través de los grupos sociales construye o resignifica los sentidos que desea socialmente transmitir. De allí que se hable de imaginarios sociales dominantes y dominados, pero en esencia, son esquemas interpretativos para el sentido social hegemónicamente impuestos haciendo plausible la vida cotidiana" (Cegarra, 2012, p. 5).

3 "El imaginario no es sólo un repertorio de imágenes sino que en él reside la subversión que protagonizan cotidiana y anónimamente las heterogéneas socialidades. También del imaginario emanan las fuerzas de mayor alcance que protagonizan el cambio o la ruptura respecto de la ordenada sociedad" (Bergua, 2005, p. 46).

4 "El registro imaginario y el registro simbólico dan lugar a dos clases de interacción social distintas: la "ceremonia ensimismada" y el "pacto comunicativo" (Avello, 1986, p. 33; citado por Bergua, 2005, p. 42).

5 Matrices de sentido existencial diría Baeza (2000; citado por Hurtado, 2004).

6 Para Bachellard la imaginación es, en sí misma, una dimensión constitutiva del ser (Solares, 2006).

7 Para Torres (2015), "Pintos construye una teoría sociológica de los imaginarios sociales (IISS) sobre pilares sociológicamente sólidos. Su planteamiento nace de un doble afán, por un lado ofrecer una teoría de la complejidad de la sociedad contemporánea. Pero a esto añade una apuesta metodológica, donde los IISS son herramientas en la descripción sociológica" (p. 2).

8 La imaginación como epicentro de la reflexión filosófica tiene sus raíces remotas en el pensamiento de Aristóteles cuando afirmó que "el alma nunca piensa sin fantasma, o sea, sin representación imaginaria. Aristóteles, a juicio de Castoriadis (1998, p. 174), descubrió dos tipos de imaginaciones: la imaginación primera, definida como: «esa potencia (o poderes) del alma que permiten a esta conocer, juzgar y pensar, así como moverse según el movimiento local». Para Aristóteles fue evidente que la imaginación era algo diferente de la sensación y el pensamiento. Claro está que sería la imaginación segunda de Aristóteles la que finalmente se instituyera en su definición más trivial y convencional, o sea aquella que la relacionaba con lo ficticio, con lo irreal, con la sensación y con las posibilidades de error" (Hurtado, 2008, pp. 85-86).

9 "La imaginación es el resultado de una capacidad psíquica específicamente humana. Manuel Antonio Baeza la define como un tipo de pensar abstracto, relativamente autónomo del terreno de lo concreto, pero que es aplicable a lo no abstracto o lo concreto, por la vía de las propias construcciones" (Dittus, 2006). 
10 Otras referencias críticas de los planteamientos de Castoriadis desde una perspectiva de izquierda en: Nassif, "Es posible conocer la realidad. Nuevos y viejos debates en el siglo XXI" (2011).

11 "Los imaginarios son el soporte de esta acción mental, y actúan como un banco de imágenes socialmente compartidas que le dan sentido a nuestro entorno existencial (Baeza, 2000). Dicho en otros términos, éstos se nutren de las experiencias cotidianas y de esta forma llenan nuestros vacíos cognitivos adquiriendo conciencia de lo pasado, lo futuro y lo presente” (Dittus, 2006, p. 167).

12 "La institución es un conjunto de significaciones legitimadas de manera social, independiente de una funcionalidad precisa; la institución, remite por lo tanto al ámbito de las aceptaciones colectivas, de las ideas, de las fantasmagorías, etc., que pasan a formar parte de nuestro sentido común” (Baeza, 200o, p. 26).

13 Para una lectura evolutiva del concepto de imaginarios sociales en Pintos, véase: Torres (2015).

14 Para M. A. Baeza, esta forma de comprender los imaginarios por Pintos implica, a su vez, que "rigen los sistemas de identificación y de integración social, $y$ que hacen visible la invisibilidad social" (Pintos, texto inédito; citado por Baeza, 20oo, p. 43).
15 "Ello quiere decir que su operación no se limita a un sistema diferenciado particular, sino que trabaja en el campo de la comunicación intersistémica en cuanto que traduce la necesidad de comprensión de los programas de un sistema por el sistema del que es entorno o en la interpretación de dos sistemas. Opera propiamente en el campo de construcción de realidad respondiendo a intereses generales, de las organizaciones particulares o de los individuos" (Pintos, 2005, p. 44).

16 El código relevancia/opacidad plantea que no existe un punto de vista privilegiado para la observación de la realidad como válido, único o verdadero, el campo de definición de la realidad siempre será limitado "ya que tendremos que asumir que diferentes perspectivas establecerán diferentes relevancias, e ignorarán diferentes opacidades" (Pintos, 2005, p. 56).

17 El texto de Pintos tenido en cuenta por Baeza en este aparte se titula Los imaginarios sociales. La nueva construcción de la realidad, de 1995. 